\title{
An Empirical Study of Avoidance of Prepositions in English Writings by Chinese Higher Vocational College Students
}

\author{
Jinbai Zhang ${ }^{1}$ \\ ${ }^{1}$ School of Arts and Science, Nanjing Institute of Industry and Technology, China \\ Correspondence: Jinbai Zhang, School of Arts and Science, Nanjing Institute of Industry and Technology, \\ Nanjing, China. E-mail: 2004100354@niit.edu.cn
}

Received: January 1, 2016 Accepted: January 21, 2016 Online Published: February 26, 2016

doi:10.5539/ells.v6n1p117 URL: http://dx.doi.org/10.5539/ells.v6n1p117

\begin{abstract}
This study investigates the avoidance of prepositions in English writings by Chinese higher vocational College students of different English proficiency levels and the main reasons for the avoidance, using English writing tasks and a questionnaire. The result indicates that the students at low English level tend to avoid using English prepositions but the students at high English level do not avoid prepositions. Low English proficiency level is the main cause of avoidance. L2 complexity, L1 and L2 differences. Psychological factors also contribute to the avoidance of English Prepositions by Chinese high vocational College students.
\end{abstract}

Keywords: avoidance, prepositions, English writings, higher vocational college

\section{Introduction}

The notion of avoidance was first put forward by Schachter (1974). Her study noticed that the number of English relative clauses produced by the Chinese and Japanese students was much less compared with the Persian and Arab students. She supposed that Chinese and Japanese students produced less relative clauses because they are not sure if they can use them correctly and so they avoid using them. She considered it a phenomenon of avoidance due to a difficulty which could be predicted by the apriori approach.

After Schachter, other researches also confirmed the prevailing existence of avoidance phenomenon in foreign language learning (Kleinmann, 1977; Dagut \& Laufer, 1985; Hulstijn \& Marchena, 1989; Kellerman, 1992). Brown (2002) divided avoidance strategy into four categories: phonological avoidance, lexical avoidance, syntactical avoidance and topic avoidance.

Many Chinese researchers have also studied the avoidance phenomenon. Some of them focus on theory analysis. Zhou \& Li (1997) discussed avoidance phenomenon in foreign language learning and puts forward some strategies coping with it. Ruan (2000) analyzes the causes of avoidance phenomenon in second language learning and provide the explanation to it based on different applied linguistics theories. His research also revealed the negative effects which avoidance phenomenon has brought about on foreign language teaching and learning.

Others Chinese researchers focus on empirical research of avoidance phenomenon. Chen (1999) examined Chinese students' avoidance of English relative clause Conditions in English writing by Sentence connection test. She explored the type of relative clauses most commonly avoided by students and the causes of their avoidance. Zhang (2007) and Guo (2013) investigated different levels of English learners for their avoidance of two types of English phrasal verbs through multiple choice test and case study. Wang (2010) conducted a study by English composition, questionnaires and interviews to explore avoidance phenomenon in the English writings of college students. Wang (2014) claimed that Chinese non-English majors tend to avoid participial adverbials in their written output during English acquisition. Chen (2014) probed into college English-majors' avoidance of compound words by multiple choice and translation test.

The previous researches have investigated the avoidance and sought to explain the causes of the avoidance from different perspectives. Compared with the domestic studies, the studies abroad on avoidance began at a relatively early time and rich research data can be found. The subjects in most studies by foreign scholars (Schachter, 1974; Kleinmann, 1977; Dagut \& Laufer, 1985; Hulstijn \& Marchena, 1989) involve both second language learners as experimental group and native speakers as control group. Their judgments of avoidance are based on the 
significant difference between the language output of the second language learners and native speakers under the same circumstances. Seliger (1989) also claimed that to demonstrate avoidance convincingly, one has to be able to show that native speakers of the L2 (the second language) would actually have used the relevant structure under the same circumstances. Norms of second language use have to be established and knowledge of the structure on the part of the learner at least in isolation has to be demonstrated.

However, it is found in Chinese scholars' researches on avoidance phenomenon that the subjects are all Chinese and no native English speakers are involved in the study (Qiu, 2004; Wang, 2010; Chen, 2014). The assumptions of avoidance phenomenon in their researches do not come from the frequency contrast of the language output between Chinese learners and native speakers. The subjects involved in the previous researches are postgraduates, university students or high school students. Nevertheless, up to now almost no research on avoidance has ever been done in the field of English writings of higher vocational college students. As higher vocational college students account for about half of the total number of college students in China, it is quite necessary to conduct a research in this field.

\section{Research Methodology}

\subsection{Research Questions}

The questions in the present study are as follows:

1) Are there any significant differences in the production of the prepositions in the English writings by Chinese higher vocational college students and native English speakers? If yes, do they suggest avoidance?

2) Are there any differences in the avoidance of the prepositions in the English writings by high-level students and low-level students in the Chinese higher vocational college?

3) What are the main reasons for the avoidance of the prepositions in the English writings by higher vocational college students?

\subsection{Subjects}

The subjects involved in this study are 15 native English speakers and 80 second-year Chinese higher vocational college students with 40 chosen from third-year English major classes and the other 40 from first-year non-English major classes, comprising native English speaker group, high-level group and low-level group.

\subsection{Instruments}

The instruments employed in this study are a writing task and a questionnaire. Writing task is based on a series of 8 pictures which tells about an animal fable. For each picture the subjects are required to write 2-4 sentences and the length of the whole writing task should reach the minimum of 250 words. The questionnaire is designed by the researcher and was expected to help find out whether the Chinese subjects have a tendency of avoiding prepositions in their English writings and what causes the avoidance. It contains two parts: the first part of the questionnaire is the personal particulars of the participants, including the name, age, gender, major and contact information. The second part, consisting of five questions, is designed to investigate the reasons for the avoidance of the prepositions in the English writings by the higher vocational college students.

\subsection{Data Collection}

The data collection of the writing task from Chinese students was conducted in their two continuous class sessions of 90 minutes under the examination condition. Students were required to discuss in Chinese instead of English and teacher did not give students any hints about the pictures in English during the discussion. After class discussion each student wrote a story on the given pictures within 45 minutes. They completed their writings independently and handed them in at the end of class. They were not allowed to use a dictionary or seek any help from their classmates. One week later, the questionnaires were handed out to the students, completed and collected within the class time.

Native English speakers were only required to do the writing task. Those who taught English writing classes wrote the compositions together with the students in class time while others wrote the compositions in their offices independently. They finished their writing tasks separately and handed in their writings to the researcher.

\subsection{Data Analysis}

Chinese students' writings are compared with those of the native English speakers to find out if any differences of the preposition production exist in the Chinese students' writings and those of the native English speakers.

In order to make the compositions in different lengths comparable, the frequency of the prepositions in each composition is calculated according to the number of the prepositions per 500 words for the purpose of 
comparison. In this way, the frequencies of prepositions of the compositions in three groups (low-level student group, high-level student group and native English speaker group) are calculated. The Statistical Package for Social Sciences (SPSS17.0) is employed for data analysis. Based on the calculated frequency results, an independent-samples t-test and one-way ANOVA are performed so as to judge if there are significant differences in the production of the prepositions by Chinese students and by native English speakers and also by the three different groups (low-level group, high-level group and native English speaker group).

According to the data retrieved from the questionnaire, the total number of different causes of avoidance selected by the subjects is counted. The different causes of avoidance are ranked in order, according to the calculated percentage.

\section{Results and Discussion}

\subsection{Research Question 1}

Are there any significant differences in the production of the prepositions in the English writings by Chinese higher vocational college students and native English speakers? If yes, do they suggest avoidance?

By the approach described in the data analysis, the comparison of preposition frequencies by the Chinese student group (low-level group + high-level group) and native English speaker group is made. As is shown in Table 1, the native English speaker group produces more prepositions than the Chinese student group. The preposition frequency mean of the native speaker group is 36.0308 , while that of the Chinese student group is 32.9033 . In order to determine whether the preposition frequencies by the two groups are significantly different, an independent-samples t-test is done, the result of which is shown in Table 2. In the Levene's test for equality of variances, $\mathrm{F}=0.125, \mathrm{Sig} .=0.725$, greater than 0.05 and it indicates that the variances of the two groups are equal at the 0.05 level. So reference should be made to the first line of the statistics "equal variances assumed" on Table 10. $\mathrm{t}=-0.971$, and the two-tailed significance is 0.335 , greater than the 0.05 , which indicates that the preposition frequencies by the native English speaker group and the Chinese student group are not significantly different.

Table 1. Preposition frequencies of the chinese student group and the native english speaker group

\begin{tabular}{lllll}
\hline Group & $\mathrm{N}$ & Mean & Std. Deviation & Std. Error Mean \\
\hline the Chinese Student & 60 & 32.9033 & 10.64418 & 1.37416 \\
Native English Speaker & 13 & 36.0308 & 9.91685 & 2.75044 \\
\hline
\end{tabular}

Table 2. Independent-Samples $\mathrm{T}$ Test on Preposition Frequencies by the Native English speakers and the Chinese students

\begin{tabular}{|c|c|c|c|c|c|c|c|c|c|}
\hline & \multicolumn{2}{|c|}{$\begin{array}{l}\text { Levene's Test } \\
\text { for Equality of } \\
\text { Variances }\end{array}$} & \multicolumn{5}{|c|}{ t-test for Equality of Means } & & \\
\hline & & & & & & & & \multicolumn{2}{|c|}{$95 \%$ Confi. Interval of Diff } \\
\hline & $\mathrm{F}$ & Sig. & $\mathrm{t}$ & df & Sig.(2-tailed) & Mean Diff. & S.E. Diff. & Lower & Upper \\
\hline Equal variances assumed & .125 & .725 & -.971 & 71 & .335 & -3.12744 & 3.21979 & -9.54751 & 3.29264 \\
\hline Equal variances not assumed & & & -1.017 & 18.504 & .322 & -3.12744 & 3.07461 & -9.57437 & 3.31950 \\
\hline
\end{tabular}

Given the result as shown in Table 2, some questions might arise: Does it suggest that Chinese higher vocational college students do not avoid using prepositions in their English writing? Why is the test result different from the previous finding that Chinese college students tend to avoid using prepositions (Chen, 2005)?

It should be noted that most prepositions occurring in compositions are free prepositions which have independent meanings. According to the meaning-oriented classification by Biber et al. (1999), prepositions are classified into two categories: free prepositions and bound prepositions. Free prepositions have an independent meaning; the choice of preposition is not dependent upon any specific words in the context. Bound prepositions often have little independent meaning, and the choice of the preposition depends upon some other word (often the preceding verb). Because the writing task is based on 8 pictures, many prepositions denoting spatial relationships (over, in, on, etc.) are used in compositions to describe the pictures, which fall into the category of free prepositions. The total number and percentages of preposition in the two categories by three groups are shown in Table 3 . 
Table 3. Total number and percentages of prepositions in two categories by three groups

\begin{tabular}{lcllll}
\hline Group & $\begin{array}{l}\text { Total Number of } \\
\text { prepositions }\end{array}$ & $\begin{array}{l}\text { Total Number of } \\
\text { FP s }\end{array}$ & $\begin{array}{l}\text { Percentage of } \\
\text { FP s }\end{array}$ & $\begin{array}{l}\text { Total Number of } \\
\text { BP s }\end{array}$ & $\begin{array}{l}\text { Percentage of } \\
\text { BP s }\end{array}$ \\
\hline Low-level (30) & 559 & 474 & $85 \%$ & 85 & $15 \%$ \\
High-level (30) & 714 & 587 & $82 \%$ & 127 & $18 \%$ \\
Native English speaker (13) & 331 & 265 & $80 \%$ & 66 & $20 \%$ \\
\hline
\end{tabular}

Note. $\mathrm{FP}=$ free preposition, $\mathrm{BP}=$ bound preposition.

According to the contrastive analysis hypothesis, those features of target language which are similar to the learners' native language would be relatively easy to acquire and those elements of the target language which are different from the learners' native language would be relatively difficult to acquire (Lado, 1957, pp. 1-2). Because free prepositions are similar in usage to their counterparts in Chinese, Chinese students would probably not avoid using them. Owing to the high percentages of free prepositions occurring in the compositions, there is no significant difference in the preposition frequencies by the native English speaker group and the Chinese student group. However, as the bound prepositions are quite different in usage from their counterparts in Chinese which often involves phrasal verbs, Chinese students will have more difficulty and avoid using them. Is it possible that Chinese students avoid certain types of prepositions only (bound prepositions in this case) instead of all types of prepositions? In order to test this hypothesis, the frequencies comparison of only bound prepositions by the Chinese student group and native English speaker group is made and test results are shown in Tables 4 and 5.

Table 4. Frequencies of bound prepositions by the Chinese student group and the native English speaker group

\begin{tabular}{lllll}
\hline Group & $\mathrm{N}$ & Mean & Std. Deviation & Std. Error Mean \\
\hline the Chinese Student & 60 & 5.4175 & 3.18711 & .41145 \\
Native English Speaker & 13 & 7.4462 & 4.36666 & 1.21109 \\
\hline
\end{tabular}

Table 5. Independent-samples $\mathrm{T}$ test on frequencies of bound prepositions by the native English speakers and the Chinese students

\begin{tabular}{|c|c|c|c|c|c|c|c|c|c|}
\hline & \multicolumn{2}{|c|}{$\begin{array}{l}\text { Levene's Test } \\
\text { for Equality of } \\
\text { Variances }\end{array}$} & \multicolumn{5}{|c|}{ t-test for Equality of Means } & \multirow{2}{*}{\multicolumn{2}{|c|}{$\begin{array}{l}95 \% \text { Confi. Interval of } \\
\text { Diff. }\end{array}$}} \\
\hline & & & & & & & & & \\
\hline & $\mathrm{F}$ & Sig. & $\mathrm{t}$ & $\mathrm{df}$ & Sig.(2-tailed) & Mean Diff. & S.E. Diff. & Lower & Upper \\
\hline Equal variances assumed & 1.419 & .238 & -1.942 & 71 & .056 & -2.02865 & 1.04479 & -4.11191 & .05461 \\
\hline Equal variances not assumed & & & -1.586 & 14.890 & .134 & -2.02865 & 1.27908 & -4.75670 & 69940 \\
\hline
\end{tabular}

However, the test result this time still fails to show a significant difference in the production of only bound prepositions by the native English speaker group and the Chinese student group. The specific category of preposition fails to produce a different test result.

There are not significant differences in the production of the prepositions in the English writings by Chinese high vocational college students as a whole and native English speakers.

\subsection{Research Question 2}

Are there any differences in the avoidance of the prepositions in the English writings by high-level students and low-level students in the Chinese high vocational college?

While the category of preposition fails to produce a different test result, it is necessary to probe into the composition of Chinese subjects for in-depth analysis.

As Chinese subjects come from two groups (i.e., low-level student and high-level student groups) at different English proficiency levels, significant differences in preposition frequency might exist between the English writings by low-level student and high-level student groups and high production of prepositions by the high-level student group may raise the level of the whole Chinese group. 
In order to test this hypothesis, the comparison of preposition frequencies by three groups (high-level student group, low-level student group and native English speaker group) is made via SPSS to investigate whether significant differences in the preposition frequency exist among the three different groups. Table 6 shows the test result $(\mathrm{F}=10.580$ and the significance $=0.000)$. It indicates that significant differences in preposition frequency exist among the three different groups.

Table 6. One-way ANOVA on preposition frequencies in the compositions by the three Groups

\begin{tabular}{llllll}
\hline & Sum of Squares & df & Mean Square & F & Sig. \\
\hline Between Groups & 1849.790 & 2 & 924.895 & 10.580 & .000 \\
Within Groups & 6119.464 & 70 & 87.421 & & \\
Total & 7969.255 & 72 & & & \\
\hline
\end{tabular}

Then post hoc multiple comparisons are made to investigate whether significant differences in preposition frequency exist between any two groups among the total three groups. As are shown in Table 7, the frequency difference between the native English speakers group and the low-level student group is statistically significant (Significance $=0.000$, smaller than 0.05), and so is the frequency difference between the low-level group and the high-level group. But the frequency difference between the high-level student group and the native English speaker group is not significant (Significance $=0.468$, greater than 0.05 ).

Table 7. Post hoc multiple comparisons of the preposition frequency

\begin{tabular}{lllllll}
\hline & & Mean & & & \multicolumn{2}{c}{ 95\% Confi. Interval of Diff } \\
\cline { 5 - 7 } (I) Group & (J) Group & Difference (I-J) & Std. Error & Sig. & Lower & Upper \\
\hline High-level & Low-level & 10.78667 & 2.41414 & .000 & 5.9718 & 15.6015 \\
& Native English speaker & 2.26590 & 3.10463 & .468 & -3.9261 & 8.4579 \\
\hline \multirow{2}{*}{ Low-level } & High-level & -10.78667 & 2.41414 & .000 & -15.6015 & -5.9718 \\
& Native English speaker & -8.52077 & 3.10463 & .008 & -14.7128 & -2.3288 \\
\hline \multirow{2}{*}{ Native English speaker } & High-level & -2.26590 & 3.10463 & .468 & -8.4579 & 3.9261 \\
& Low-level & 8.52077 & 3.10463 & .008 & 2.3288 & 14.7128 \\
\hline
\end{tabular}

In summary, there are significant differences in the production of the prepositions in the English writings by native English speakers and low-level students but not such differences in the English writings by native English speakers and high-level students. While low-level group display an avoidance of prepositions in their English writings, the avoidance of prepositions is not found in the English writings of high-level group. The test result also indicates that the preposition frequencies in English writings by the low-level group and the high-level group are significantly different. The high-level group produces much more prepositions in the compositions than the lower-score group does.

Such a result is similar to Zhang Bin's findings about the avoidance of English phrasal verbs (PVs) by Chinese learners of English (2007). Zhang reports that there are significant differences in the frequency of the PVs used by native English speakers and by low-level students, but not such differences in the PV frequency by native English speakers and by high-level students. Only low-level students display an avoidance of PVs.

\subsection{Research Question 3}

Avoidance phenomena do exist in English writings of the Chinese vocational college students. What are the factors leading to their avoidance in the English writings? The questionnaire is designed to investigate the reasons for avoidance of prepositions and the data retrieved from the questionnaire are shown in Table 8 . 
Table 8. Descriptive statistics of the reasons for avoidance of prepositions

\begin{tabular}{lll}
\hline Reasons for Avoidance & $\begin{array}{l}\text { Number of students approving the reason / } \\
\text { Total Number of students }\end{array}$ & Percentage \\
\hline Low English Proficiency & $14 / 30$ & $47 \%$ \\
L1-L2 Difference & $6 / 30$ & $20 \%$ \\
L2 Complexity & $3 / 30$ & $10 \%$ \\
Avoid making errors & $14 / 30$ & $47 \%$ \\
Lack confidence & $10 / 30$ & $33 \%$ \\
finish the writing task & $8 / 30$ & $27 \%$ \\
Get good marks in exams & $13 / 30$ & $43 \%$ \\
\hline
\end{tabular}

\subsubsection{English Proficiency}

As shown in Table 8, among all factors, English proficiency is the main factor leading to the avoidance of prepositions, as $47 \%$ of the subjects from low-level group claim that they avoid using prepositions because they have not learned them well.

Such an introspection by the subjects suggests that English proficiency plays an important role in the avoidance of prepositions, which complies with the finding under research question 2. According to the test result from the comparison of preposition frequencies by three groups (high-level student group, low-level student group and native English speaker group) made via SPSS, low-level group display an avoidance of prepositions in their English writings but high-level group does not. It is also found in present study that students do not avoid using such bound prepositions as "(be interested) in", "(agree) with" and "(listen) to" in their compositions because they are very familiar with these prepositions occurring with high frequency. Likewise, Zhang Bin (2007) claims that English proficiency level is an influential factor in the avoidance of PVs. Most Chinese learners do not avoid using PVs such as "get up" for the same reason. They have to use them so frequently that they are very familiar with their usage.

\subsubsection{Linguistic Factors}

As Table 8 suggests, besides English proficiency level, L1-L2 difference and L2 complexity also contribute to the avoidance of prepositions in the English writings of Chinese vocational college students.

L1-L2 difference, chosen by $20 \%$ of the subjects from low-level group, is ranked before L2 complexity among the reasons for avoiding prepositions. L1-L2 difference has been widely acknowledged as one of important reasons for avoidance. Schachter states (1974) that the avoidance of relative clauses by Chinese and Japanese speakers is due to the difficulty caused by syntactic difference between their mother tongues and English. Relative clauses in both Chinese and Japanese are prenominal (i.e., the relative clause occurs in front of the head noun phrase), while relative clauses in English are postnominal (i.e., the relative clause occurs behind the head noun phrase) (Schachter, 1974, p. 210).

Only $10 \%$ of the subjects from low-level group choose L2 complexity as their reasons for avoiding using prepositions in their English writing. However, it is hasty to conclude that this factor weighs less in the role of influencing the avoidance of prepositions. The subjects may be frustrated by the ambiguous distinction between L1-L2 difference and L2 complexity when they make choices from the linguistic factors contributing to the avoidance of prepositions. English prepositions arc characterized by polysemy, multi-function and high-frequency, which make prepositions a complex target language item for Chinese students. According to statistics, while there are 280 prepositions or preposition phrases in English, there are only less than 30 prepositions frequently used in Chinese ( $\mathrm{Li}, 2013$, p. 56). The big difference in the quantity of prepositions being used in two languages also adds to the complexity of prepositions of English. Although it is hard to judge which linguistic factor weighs more in the role of influencing the avoidance of prepositions, it is certain that both L1-L2 difference and L2 complexity are important factors contributing to avoidance of prepositions.

\subsubsection{Psychological Factors}

Among all the reasons, avoiding making errors is selected by $47 \%$ of subjects from low-level group as the top reason for the avoidance of prepositions. Such a result complies with Schachter' definition of avoidance as the way second language learners deal with some difficulties in the learning process passively by giving up the use of some structures or words so as to ensure the correctness of language (1974, p. 210). Lack of confidence is also an important reason for the avoidance of prepositions, acknowledged by $33 \%$ of the subjects from low-level 
group. $27 \%$ of the subjects tend to avoid using difficult words or structures in English writing because they feel it easy to finish the writing tasks with simple expressions.

\subsubsection{The Influence of Tests}

The result of the questionnaire also shows that 13 subjects from low-level group agree that they tend to use less complex words and structures under exam or test conditions than in ordinary learning environment. $43 \%$ of the subjects demonstrate an avoidance tendency under exam or test conditions, which indicates the testing environment has an important effect on the avoidance. Such a result is reported to be closely related with the scoring criteria of English writing test (Chen, 2005, p. 13). Taking PRETCO (Practical English Test for Colleges) as example, students' writing work is mainly judged by the completeness of the content and the correctness of the language. Because the writing task of PRTECO is practical writing such as notice and business letter and the content is given in Chinese, most of the students can achieve the completeness of the content. As a result, both teachers and students give first priority to the correctness of language in writing. In order to get higher scores, many students tend to give up difficult words or structures to avoid making errors. This kind of avoidance will have negative effects on improving students' writing skill.

\section{Conclusions}

Through the analysis of the collected data from the writing tasks and questionnaires, the main findings are summarized as following:

(1) There are not significant differences in the production of the prepositions in the English writings by native English speakers and Chinese high vocational college students as a whole.

(2) The high-level students in Chinese high vocational colleges produce much more prepositions in the compositions than the low-level students. Only the high-level students display avoidance of prepositions in their English writings but the low-level students do not.

(3) Many factors account for avoidance of prepositions, among which is English proficiency of learners, psychological and linguistic factors. The most influential is learners' language proficiency. Avoiding making errors and lack of confidence are two major psychological factors contributing to avoidance. L2 Complexity and L1-L2 Difference are considered as two linguistic factors affecting avoidance. Finally, the scoring criteria of tests have an important effect on the avoidance.

\section{Acknowledgements}

The research is supported by social science foundation of Nanjing Institute of Industry and Technology "An Empirical Study of Avoidance Phenomenon in English writings by Chinese Higher Vocational College students" (Grant NO.YK15-05-02).

\section{References}

Biber, D., Johansson, S., Leech, G., Conrad, S., \& Finegan, E. (Eds.). (1999). Longman grammar of spoken and written English. London: Longman.

Brown, H. D. (Ed.). (2002). Principles of Language Learning and Teaching (3rd ed.). Beijing: Foreign Language Teaching and Learning Press.

Chen, C. Y. (2014). A study of avoidance phenomenon of English compound words by Chinese students of English majors. College English, 11(1), 98-104.

Chen, Y. H. (1999). Why Chinese avoid using relative clauses in their English learning. Fujian Foreign Language, 1, 49-55.

Chen, Z. X. (Ed.). (2005). Avoidance of prepositions in compositions written by Chinese students. Unpublished master's thesis, Shandong University, Jinan, Shandong.

Dagut, M., \& Laufer, B. (1985). Avoidance of phrasal verbs - a case for contrastive analysis. Studies in Second Language Acquisition, 7, 73-79. http://dx.doi.org/10.1017/S0272263100005167

Guo, W. (2013). An empirical study of avoidance of English phrasal verbs by Chinese learners of English. Journal of PLA University of Foreign Languages, 36(4), 73-77.

Hulstijn, J., \& Marchena, E. (1989). Avoidance: Grammatical or semantic causes. Studies in Second Language Acquisition, 11, 241-255. http://dx.doi.org/10.1017/S0272263100008123

Kellerman, E. (Ed.). (1992). Another Look at an Old Classic: Schachter's Avoidance. Tokyo: Temple University. 
Kleinmann, H. H. (1977). Avoidance Behavior in Adult Second Language Acquisition. Language Learning, 27, 93-107. http://dx.doi.org/10.1111/j.1467-1770.1977.tb00294.x

Lado, R. (Ed.). (1957). Linguistics across Cultures. Ann Arbor, MI: University of Michigan Press.

Li, Q. (2013). An exploration to the usage of preposition in English writing by Chinese college students from the perspective of language transfer. Journal of Tianjin Foreign Studies University, 20(4), 56-61.

Qiu, J. X. (2004). A Study of Avoidance Phenomenon in the English Classroom. Journal of Zhejiang Education Institute, 3, 84-90.

Ruan, Z. L. (2000). An analysis of avoidance phenomenon in the second language learning. Foreign Language Education, 21(1), 19-23.

Schachter, J. (1974). An error in error analysis. Language Learning, 24, 206-219. http://dx.doi.org/10.1111/j.1467-1770.1974.tb00502.x

Seliger, H. (1989). Semantic constraints on the production of English passive by Hebrew-English bilinguals. In H. Dechert \& M. Raupach (Eds.), Transfer in language production (pp. 21-33). Norwood, NJ: Ablex.

Wang, J. B. (2010). An investigation of avoidance phenomenon in English writings by Chinese college students. Foreign Language Education, 31(5), 55-59.

Wang, N. Y. (2014). Low production and avoidance of participial adverbials in Chinese-English Translation. Joumal of Nanjing University of Aeronautics and Astronautics (Social Sciences), 16(1), 73-76.

Zhang, B. (2007). An investigation of avoidance of English phrasal verbs by Chinese Learners of English. Journal of PLA University of Foreign Languages, 30(6), 60-64.

Zhou, R., \& Li, Z. M. (1997). The avoidance phenomenon in foreign language studies. Journal of Southwest Normal University, 1, 118-121.

\section{Copyrights}

Copyright for this article is retained by the author(s), with first publication rights granted to the journal.

This is an open-access article distributed under the terms and conditions of the Creative Commons Attribution license (http://creativecommons.org/licenses/by/3.0/). 